\title{
Photosynthetic gas exchange responses of Swietenia macrophylla King and Melia azedarach L. plantations under drought conditions
}

\author{
Hong-Chyi Jhou', Ya-Nan Wang ${ }^{2}$, Chung-Shien Wu ${ }^{3}$, Jui-Chu Yu ${ }^{1}$ and Chung-I Chen ${ }^{2 *}$ (i)
}

\begin{abstract}
Background: The environmental stresses caused by climate change have become more severe in recent decades, affecting tree growth and physiology. Tropical forests have great potential for global carbon sequestration. However, they suffer from heavy rainfall and prolonged dry periods due to climate change. Swietenia macrophylla King and Melia azedarach $\mathrm{L}$. are economically valuable trees that are widely planted in southern Taiwan. Plantations are exposed to either prolonged dry periods or heavy rainfall within the seasons of tropical monsoon areas. Photo-physiological comparisons may provide information that can improve management of S. macrophylla and M. azedarach plantations in tropical regions.

Results: Both species exhibited a midday depression in leaf photosynthesis regardless of the season. The net photosynthetic rate $\left(P_{N}\right)$, stomatal conductance $\left(g_{\mathrm{s}}\right)$, and transpiration rate $(E)$ in the dry season all significantly decreased in both tree species. In addition, M. azedarach used water more efficiently than did S. macrophylla during the dry season, but S. macrophylla had higher $P_{N}$ compared with that in M. azedarach during the wet season. Temperature and vapor pressure deficit influenced $P_{N}$ variation in S. macrophylla and $M$. azedarach, respectively. Our data suggested that the $P_{\mathrm{N}}$ and $g_{\mathrm{s}}$ of $M$. azedarach, but not of $S$. macrophylla, were linearly correlated during the dry season. The reduction of the leaf area was more sever in M. azedarach than in S. macrophylla, thus preventing water loss more efficiently.

Conclusions: $M$. azedarach adapted to drought by reducing total leaf area and maintaining higher $P_{N}, g_{s^{\prime}} E$, and WUE compared with those measured in S. macrophylla during the dry season. M. azedarach is more drought adaptation and more suitable for both humid and semi-humid areas than S. macrophylla, whereas the latter should be limited to more humid areas.
\end{abstract}

Keywords: Photosynthesis, Prolonged drought, Soil water content, Stomatal conductance, Transpiration rate, Vapor pressure deficit

\section{Background}

Global climate change has increased the incidence and severity of extreme climate events such as droughts and high temperatures (IPCC 2015), which strongly affect plant physiology and growth. Numerous reports

\footnotetext{
*Correspondence: rk.aee@msa.hinet.net

2 Department of Forestry and Resource Conservation, National Taiwan University, 10617 Taipei, Taiwan

Full list of author information is available at the end of the article
}

have emphasized that water stress negatively affects gas exchange, which often results in lower leaf photosynthesis, stomata conductance, and transpiration (Ogaya and Peñuelas 2003; Leuzinger et al. 2005; Guerfel et al. 2009; Li et al. 2016). Decreased leaf photosynthesis can be caused by either stomatal or non-stomatal limitations (Taiz and Zeiger 2002). Therefore, the measurement of gas exchange in plants could reflect the physiological response to environmental conditions and the relationship between gas exchange and environmental variables 
could provide a more detailed understanding of how environmental variables limit photosynthesis, growth performance, and biomass (Ishida et al. 1996).

Tropical forests play an important role in the global carbon cycle because they account for a large part of terrestrial net primary productivity, while covering a lesser part of the global land surface (Slot and Winter 2017). Tropical areas experience wet seasons (in the summer) with heavy rainfall and prolonged dry seasons (in the winter), which can strongly affect plant distribution and growth (Engelbrecht et al. 2006). Taiwan's subtropical climate is characterized by an average annual rainfall of $>2500 \mathrm{~mm}$, with heterogeneous distribution across the seasons and geographical areas. In particular, southern Taiwan has had increasingly frequent high temperatures and rainstorms followed by extended droughts. These conditions greatly affect tree growth in the area. To better understand how these changing environmental factors affect plant growth in this region, we estimated gas-exchange variables in two Meliaceae tree species that are widely planted in southern Taiwan: Swietenia macrophylla King and Melia azedarach L. The semi-deciduous S. macrophylla originated from Central and South America, and it is a major forestation species of high economic value in the Taiwanese lumber industry (Grogan et al. 2005). Although generally characterized by shade intolerance, $S$. macrophylla seedlings are able to grow in the forest understory (Grogan et al. 2005; Cordeiro et al. 2009). The deciduous $M$. azedarach, a native to Taiwan and South China, is fast-growing and shade-intolerant, with leaves and fruits that contain insecticidal compounds. The species is also harvested for its high-quality wood (Kuo et al. 2004; Liao et al. 2004), making it a popular species to cultivate. Both species have shallow root systems that are characteristic of many tropical trees (Toky and Bisht 1992; Dünisch et al. 2003).

Several researches demonstrated that different species adopt different strategies in response to seasonal environmental conditions (Sun et al. 2011; Koller et al. 2013; Arndt et al. 2015). For example, gas exchange rate, water use efficiency, chlorophyll fluorescence and seasonal defoliation fluctuate among seasons and species. Thus, preliminary observations revealed that both species exhibited stronger growth than other species in the study site in southern Taiwan (Chen et al. 2013, 2016a), but still showed a poor growth performance compared with those cultivated in other regions in Taiwan, Brazil, and China. The aim of the present study was to assess the vulnerability of both commercial species to environmental stresses. We hypothesized that the two species may adopt different strategies to adapt to water stress that affect the growth and physiology of plantations under field conditions. Rather than performing a single, instantaneous measurement, we chose to chart the daily and seasonal variation in gas exchange because time-course data provide more reliable information on photosynthetic productivity (Yin et al. 2006). Our results will contribute information that can improve management of S. macrophylla and M. azedarach plantations in tropical regions.

\section{Methods \\ Plant material and growing conditions}

The experimental plantation used for this study is located on the Wan-Long Farm, which belongs to the Pingtung operation branch, Taiwan Sugar Corporation in Sinpi Township, Pingtung, Taiwan $\left(120^{\circ} 36^{\prime} 30^{\prime \prime}\right.$ E, $22^{\circ} 31^{\prime} 26^{\prime \prime} \mathrm{N}$; $69 \mathrm{~m}$ above sea level). The total area of the plantation in the farm is approximately $291 \mathrm{ha}$, and the soil consists of a sandy loam. The study site experiences a typical tropical monsoon climate, with a high frequency of typhoons and late thundershowers in the summer and little precipitation in other seasons. The mean monthly daytime air temperatures for March, June, September, and December in 2010 were $25.1,29.1,28.6$, and $23.1{ }^{\circ} \mathrm{C}$, respectively; they were measured at a meteorological station located $50 \mathrm{~m}$ west of the experimental site. The annual precipitation from 2005 to 2010 was estimated to be 2300$3800 \mathrm{~mm}$, with the majority of the rainfall concentrated in the months between May and September. For example, $92 \%$ of the total annual precipitation in 2010 happened between May and September, and the dry season lasted for over half a year (accumulated rainfall between October 2009 and April 2010 was only $~ 70 \mathrm{~mm}$ ). Based on the climate diagrams of this site, the wet season was defined to last from May to September and the dry season in the remaining months.

At the experimental plantation, 14 broadleaved tree species were planted between 2002 and 2005, and S. macrophylla and $M$. azedarach were planted in 2002. Irrigation and fertilization were applied in the first few years after afforestation. Additionally, pruning and mowing were also applied annually in late summer. Generally, $M$. azedarach defoliates in February and sprouts new leaves and buds in March, whereas S. macrophylla defoliates partially in March. The trees were planted in the same plot, which was subdivided by species. For the experiment, we selected trees located at a subplot boundary so that the two species were side-by-side with $2.5 \mathrm{~m}$ distance between each other. The average diameter at breast height (DBH) and total height of S. macrophylla and $M$. azedarach in the experimental plot are presented in Table 1. In 2009, S. macrophylla and M. azedarach stand densities were 1111 and 1420/ha, and in 2010, they were 1070 and 1413/ha, respectively. The survival rates of $S$. macrophylla and $M$. azedarach on the plantation were 96.3 and $99.5 \%$, respectively. 
Table 1 Average values ( \pm standard error) of diameter at breast height (DBH), height $(\mathrm{H})$, and number of samples (N) for Swietenia macrophylla and Melia azedarach in 2010

\begin{tabular}{lll}
\hline & S. macrophylla & M. azedarach \\
\hline $\mathrm{DBH}(\mathrm{cm})$ & $9.90 \pm 2.88 \mathrm{~b}$ & $11.86 \pm 4.14 \mathrm{a}$ \\
$\mathrm{H}(\mathrm{m})$ & $9.12 \pm 1.96 \mathrm{a}$ & $9.43 \pm 1.90 \mathrm{a}$ \\
$\mathrm{N}$ & 69 & 104 \\
\hline
\end{tabular}

Means followed by different lowercase letters differ significantly between seasons at $P<0.05$

Leaf area index (LAI) is a dimensionless quantity variable of the forest canopy defined as the one-sided leaf surface area per ground surface area. Monthly measurements of the LAI per species were taken simultaneously for the top and under canopy of three sample trees at dusk using a plant canopy analyzer (LAI-2200, LI-COR, Lincoln, NE, USA).

\section{Measurement of gas-exchange variables}

Diurnal gas exchange was measured once a month in 2010. We measured a group of ambient variables [photosynthetic photon flux densities (PPFD), leaf-air vapor pressure deficit $\left(\mathrm{VPD}_{1}\right)$, leaf temperature $\left(T_{1}\right)$, ambient $\mathrm{CO}_{2}$ concentration $\left(\mathrm{CO}_{2}\right)$ ] that could influence diurnal gas exchange and estimated physiological variables [net photosynthetic rate $\left(P_{\mathrm{N}}\right)$, stomatal conductance $\left(g_{\mathrm{s}}\right)$, transpiration rate $(E)$, intercellular $\mathrm{CO}_{2}$ concentration $\left(C_{\mathrm{i}}\right)$, water use efficiency (WUE)] on four dates within a typical season during 2010: late dry season (27 March), early wet season (26 June), late wet season (25 September), and early dry season (30 December). Data were recorded in the field using two portable photosynthesis systems (LI6400-sun-sky, LI-COR, USA). For all measurements, the leaves were placed in in the chamber (LI-6400-08), using a clump-on leaf cuvette; the chamber was covered with transparent film at the top to ensure that ambient light of equal intensity reached the leaves. WUE was estimated as $P_{\mathrm{N}} / E$.

Gas-exchange variables were measured in three fully expanded leaves per sampled tree under direct sunlight each hour from 08:00 to 16:00, on the same day in the three sampled trees per species. Because of the limited time available for each measurement, we sampled three nearby trees per species in the same plot. The ambient air temperature was recorded during each sampling, as was the ambient $\mathrm{CO}_{2}$, which was approximately 394 , 376, 389, and 395 ppm on March 27, June 26, September 25, and December 30, 2010, respectively. The average daytime PPFD above canopy was $1739 \pm 667$, $1762 \pm 800,1520 \pm 856$, and $1413 \pm 528 \mu$ mol photons/ $\mathrm{m}^{2} / \mathrm{s}$ in March, June, September, and December, 2010, respectively. The light saturation points of $S$. macrophylla during winter, spring, summer, and autumn were 500, 750,1000 , and $500 \mu \mathrm{mol}$ photons $/ \mathrm{m}^{2} / \mathrm{s}$, respectively, and in $M$. azedarach, they were 500, 500, 1200, and $500 \mu \mathrm{mol}$ photons $/ \mathrm{m}^{2} / \mathrm{s}$ during the same respective seasons. These values were estimated by measuring the seasonal light response curve in 2011 (data not shown). Soil water content (SWC) and relative humidity $(\mathrm{RH})$ were continuously recorded at a meteorological station $50 \mathrm{~m}$ west of the sampled tree plantation using a time-domain reflectometer (CS616; Campbell Scientific Inc., Logan, UT, USA) and a relative humidity probe (HMP45C; Vaisala, Finland). The soil water content device was placed $20 \mathrm{~cm}$ underground and the humidity probe was set $9 \mathrm{~m}$ aboveground. According to the previous research conducted in this site, the soil profile was shallow ( $<40 \mathrm{~cm}$ depth) (Cheng et al. 2016). The optimum temperature of photosynthesis is generally between 25 and $30{ }^{\circ} \mathrm{C}$. Thus, we set $30{ }^{\circ} \mathrm{C}$ as the break point.

\section{Data analysis}

Collected data were analyzed in SAS 9.3 (SAS Institute Inc., Cary, NC, USA). Pearson's correlation was used to examine the relationship between photosynthetic variables and environmental factors. Duncan's multiple range tests were run a posteriori to test the difference among the seasons and species. Significance was considered at $P<0.05$ and 0.01 . Regression and curve-fitting analyses were performed using SigmaPlot 12.0 (Systat Software Inc, San Jose, CA, USA). The relation among gas exchange parameters was analyzed using the monthly measurement data. Data are presented as mean \pm standard error.

\section{Results}

\section{Environmental conditions}

The annual rainfall was $2848.5 \mathrm{~mm}$ in 2010 , and the average annual rainfall was $2764.5 \mathrm{~mm}$ during the $2008-2010$ period. The recorded rainfall varied considerably in 2010 from a maximum of $1178.5 \mathrm{~mm}$ in September to a minimum of $2.5 \mathrm{~mm}$ in March. A typhoon was the primary cause of the high rainfall volume in September. The accumulated rainfall from May to September accounted for more than $92 \%$ of the annual precipitation, confirming that these months constituted the wet season (Fig. 1). In addition, the fluctuations in SWC and RH also reflected the rainfall volume. Although the precipitation was mainly concentrated between May and September, the SWC and RH were increased from May to October represented the pattern of time lag. For example, both SWC and RH were the highest in September but then decreased drastically in November and December when the precipitation was approximately zero. 


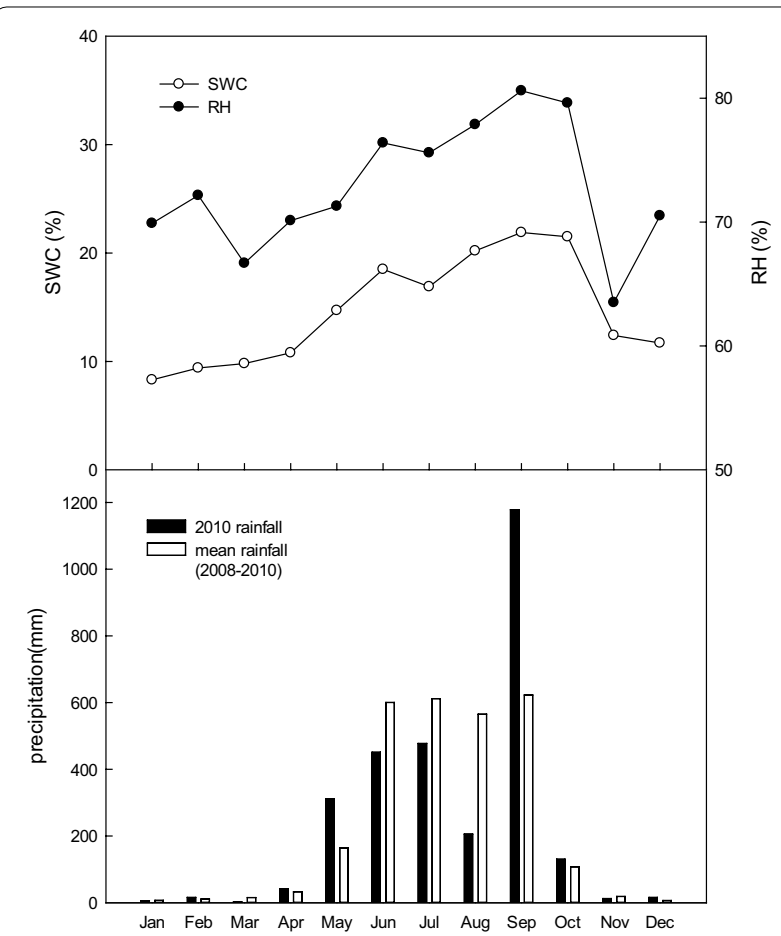

Fig. 1 Monthly changes in soil water content (SWC), relative humidity (RH), and rainfall in 2010, and the mean rainfall between 2008 and 2010

Across all seasons, PPFD gradually increased throughout the morning and then decreased after noon. March and December air temperatures $\left(T_{\mathrm{a}}\right)$ peaked at $30.7{ }^{\circ} \mathrm{C}$ (12:00) and $31.1{ }^{\circ} \mathrm{C}(10: 00)$, respectively. The highest $T_{\mathrm{a}}$ of the year $\left(38.1{ }^{\circ} \mathrm{C}\right)$ occurred in June at 13:00, but the highest PPFD was measured in September at 13:00, when the maximum $T_{\mathrm{a}}$ was $34.3^{\circ} \mathrm{C}$ (Fig. 2). The highest $\mathrm{VPD}_{\mathrm{a}}$ for each season was $3.31 \mathrm{kPa}$ at 11:00, $4.22 \mathrm{kPa}$ at 11:00, $3.88 \mathrm{kPa}$ at 13:00, and $3.38 \mathrm{kPa}$ at 11:00 on 27 March, 26 June, 25 September, and 30 December, respectively.

\section{Gas exchange in leaves}

Overall, the $g_{\mathrm{s}}$ and $E$ values of both species were higher in the wet season than in the dry season. Interestingly, the two species had distinct $P_{\mathrm{N}}$ values across all seasons. In the dry season, the $S$. macrophylla $P_{\mathrm{N}}$ was low, but in the wet season, it increased by nearly fourfold from 08:00 to 13:00, and then decreased drastically (Fig. 3). In $M$. azedarach, however, the seasonal variation of $P_{\mathrm{N}}$ was indistinct (Fig. 3). As a result, $M$. azedarach had higher $P_{\mathrm{N}}$ than S. macrophylla in the dry season, but lower $P_{\mathrm{N}}$ in the wet season.

The two species had similar $g_{\mathrm{s}}$ values in the dry season, but in the wet season, $M$. azedarach had higher $g_{\mathrm{s}}$ than S. macrophylla throughout the day (Fig. 3). The lowest $g_{\mathrm{s}}$ values were 0.0041 and $0.0024 \mathrm{mmol} \mathrm{H}_{2} \mathrm{O} / \mathrm{m}^{2} / \mathrm{s}$ in the

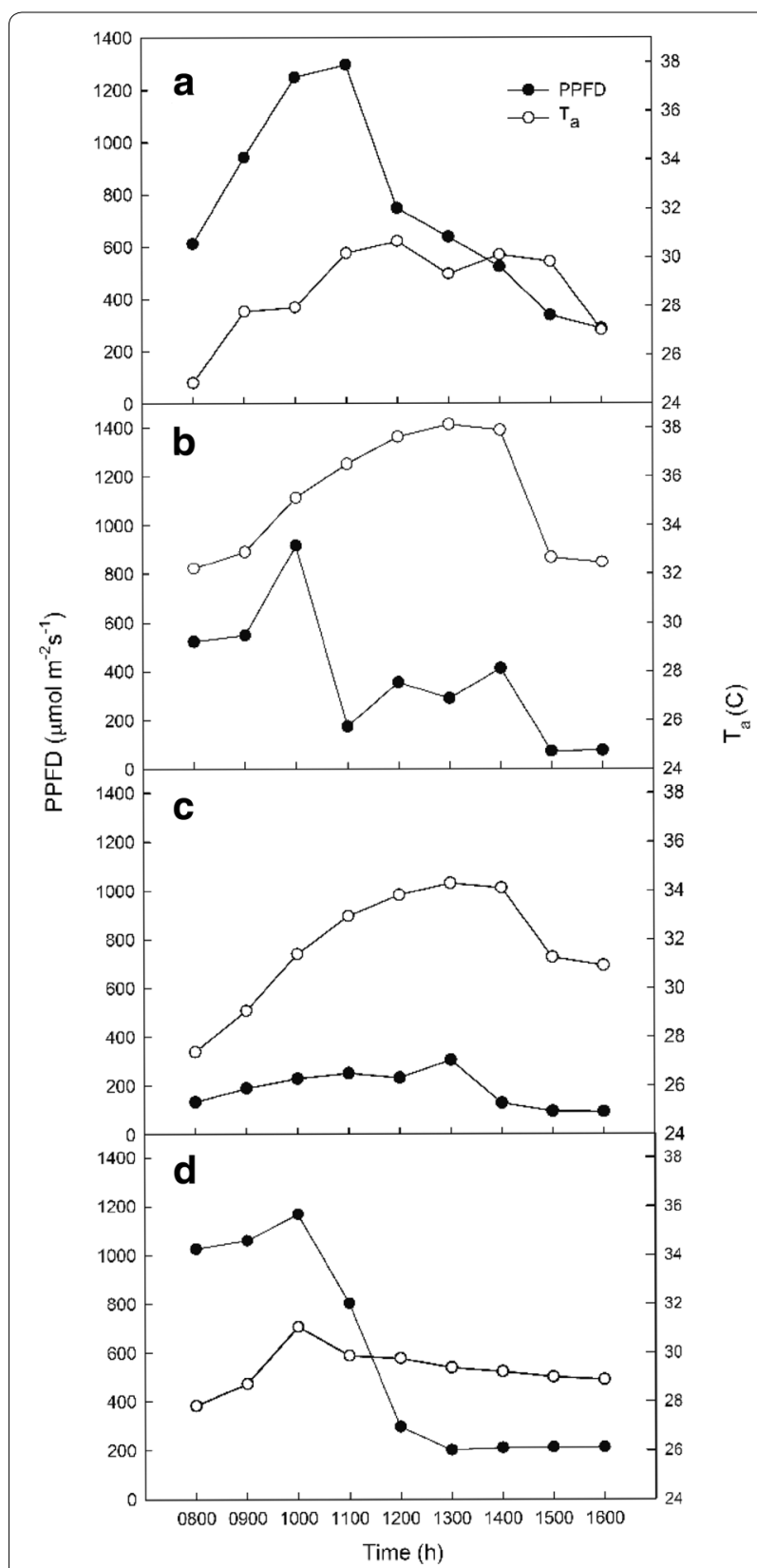

Fig. 2 Diurnal variation in photosynthetic photon flux density (PPFD) and air temperature $\left(T_{a}\right)$ in 2010: late dry season (27 March; $\mathbf{a}$ ), early wet season (26 June; b), late wet season (25 September; $\mathbf{c}$ ), and early dry season (30 December; $\mathbf{d}$ )

late dry season and early dry season, respectively. Variation in $C_{\mathrm{i}}$ was the opposite of $P_{\mathrm{N}}$, with $S$. macrophylla exhibiting higher $C_{\mathrm{i}}$ values in the dry season than in the wet season (Fig. 3). A comparison of diurnal WUE revealed that $M$. azedarach had significantly higher values than S. macrophylla in the dry season, but the differences between the species were less in the wet season (Fig. 3). The $\mathrm{VPD}_{1}$ increased from 8:00 to 11:00 in the dry 


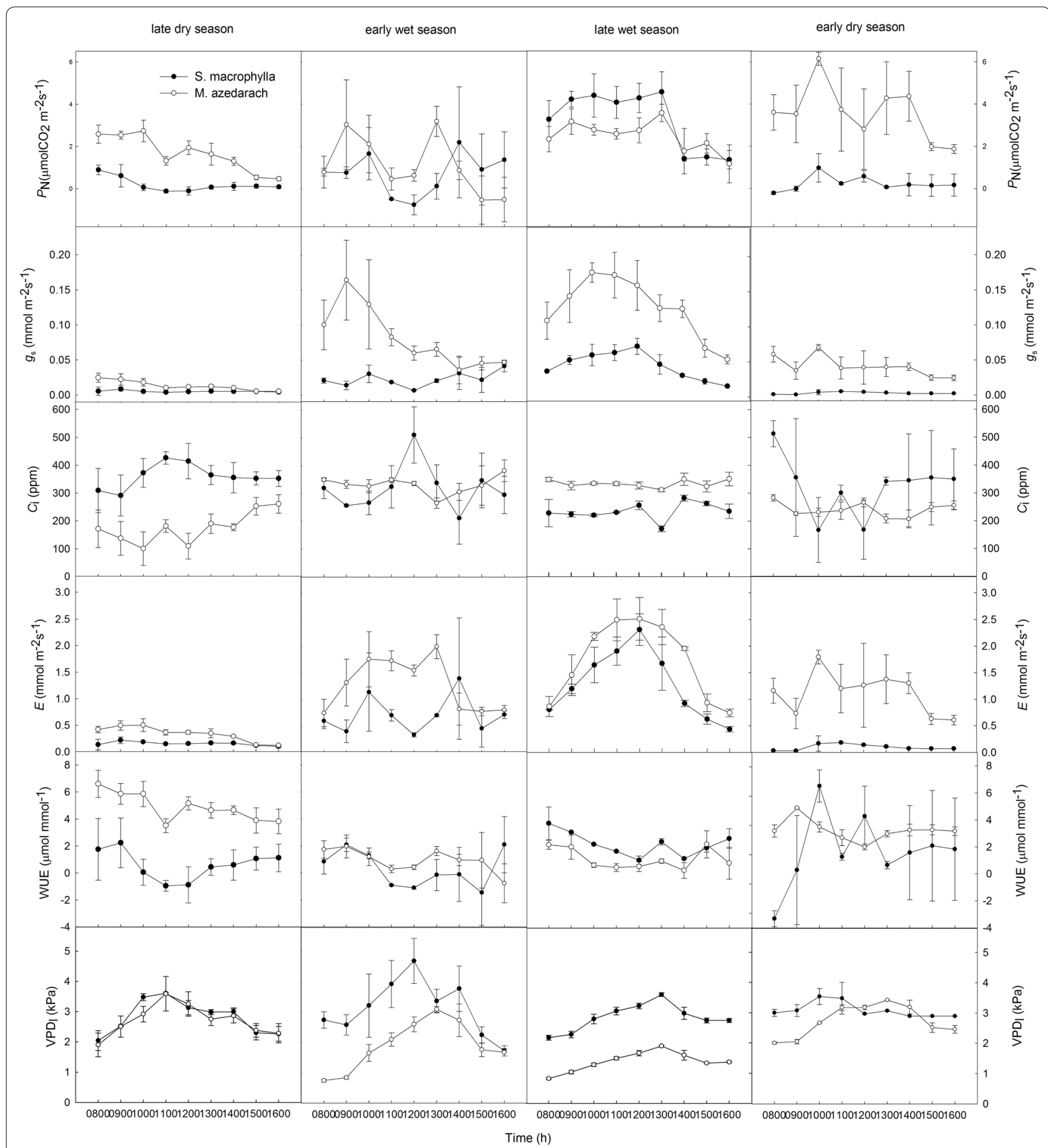

Fig. 3 Diurnal variation in gas exchange in Swietenia macrophylla and Melia azedarach in 2010. Net photosynthetic rate $\left(P_{N}\right)$, stomatal conductance $\left(g_{s}\right)$, intercellular $\mathrm{CO}_{2}$ concentration $\left(C_{\mathrm{i}}\right)$, water use efficiency $(\mathrm{WUE})$, and leaf-air vapor pressure deficit $\left(\mathrm{VPD}_{\mathrm{I}}\right)$, late dry season (27 March), early wet season (26 June), late wet season (25 September), and early dry season (30 December). Data are represented as the mean $\pm \mathrm{SE}(N=3)$

season, whereas the increase continued until 13:00 in the wet season (Fig. 3). These results show that the gas exchange of both species was representative of different patterns in response to drought conditions.
During the dry season, $P_{\mathrm{N}}$ had a significantly negative correlation $(P<0.01)$ with $C_{\mathrm{i}}$ in both species. Furthermore, in S. macrophylla, the $P_{\mathrm{N}}$ was negatively correlated $(P<0.05)$ with $T_{\mathrm{l}}$, while in $M$. azedarach, the $P_{\mathrm{N}}$ value 
was positively correlated with $\mathrm{VPD}_{1}$ and PPFD $(P<0.01)$. During both seasons, the correlation between $g_{\mathrm{s}}$ and $C_{\mathrm{i}}$ was significantly positive in $M$. azedarach $(P<0.01)$ but not in $S$. macrophylla. During the wet season, $S$. macrophylla $P_{\mathrm{N}}$ exhibited a significant positive correlation $(P<0.01)$ with $g_{\mathrm{s}}$ and $E$, but a negative correlation $(P<0.01)$ with $T_{\mathrm{a}}$ and $T_{1}$ (Table 2). There was no significant correlation between the gas exchange variables and $\mathrm{CO}_{2}$ in S. macrophylla regardless of the season. However, in $M$. azedarach the $\mathrm{CO}_{2}$ content significantly and positively correlated with $\mathrm{g}_{\mathrm{s}}(P<0.05)$ and $\mathrm{C}_{\mathrm{i}}(P<0.01)$ during the dry season, but exhibited a negative correlation with $E$ in the wet season $(P<0.01)$.

Seasonal LAI variation was different between the species (Table 3). LAI was higher in S. macrophylla than in $M$. azedarach throughout all seasons. S. macrophylla exhibited no significant difference between seasons, although this difference was slightly higher during the wet season. In contrast, $M$. azedarach exhibited a significantly higher LAI in the early wet season than in the late dry season.

Figure 4 depicts the relationship between $g_{\mathrm{s}}$ and the gas-exchange variables. We observed a linear relationship between $P_{\mathrm{N}}$ and $g_{\mathrm{s}}$ in S. macrophylla, but a parabolic relationship between these factors in $M$. azedarach (Fig. 4a). The $g_{\mathrm{s}}$ and $E$ values in both species exhibited a significant linear correlation $(P<0.01)$, with the slope for $S$. macrophylla being higher than that for M. azedarach (Fig. 4b). The relationship between $g_{\mathrm{s}}$ and $C_{\mathrm{i}}$ was distinctly parabolic in both species; in $S$. macrophylla for example, the relationship was a quadratic polynomial, with a decrease
Table 3 Mean values ( \pm standard error) of leaf area index (LAI) of Swietenia macrophylla and Melia azedarach in different seasons

\begin{tabular}{lll}
\hline Seasons & S. macrophylla & M. azedarach \\
\hline Late dry & $2.53 \pm 0.18 \mathrm{a}$ & $1.30 \pm 0.55 \mathrm{~b}$ \\
Early wet & $3.21 \pm 0.42 \mathrm{a}$ & $3.04 \pm 0.24 \mathrm{a}$ \\
Late wet & $3.26 \pm 0.96 \mathrm{a}$ & $2.77 \pm 0.77 \mathrm{ab}$ \\
Early dry & $2.75 \pm 0.19 \mathrm{a}$ & $1.79 \pm 0.18 \mathrm{ab}$ \\
\hline
\end{tabular}

Means followed by different lowercase letters differ significantly between seasons at $P<0.05$

in $C_{\mathrm{i}}$ when $g_{\mathrm{s}}$ was less than $0.05 \mathrm{~mol} / \mathrm{m}^{2} / \mathrm{s}^{1}$ and an increase in $C_{\mathrm{i}}$ when $g_{\mathrm{s}}$ was greater than $0.05 \mathrm{~mol} / \mathrm{m}^{2} / \mathrm{s}$. In contrast, $g_{\mathrm{s}}$ and $C_{\mathrm{i}}$ in $M$. azedarach were positively correlated under drought conditions, whereas, in the wet season, $C_{\mathrm{i}}$ remained constant as $g_{\mathrm{s}}$ increased (Fig. $4 \mathrm{c}$ ). We observed a curvilinear relationship between $g_{\mathrm{s}}$ and $\mathrm{VPD}_{1}$ in $M$. azedarach $(P<0.01)$, while $g_{\mathrm{s}}$ decreased sharply when $\mathrm{VPD}_{1}$ was over $1.5 \mathrm{kPa}$. This relationship was not significant in S. macrophylla (Fig. 4d).

The linear relationship between $P_{\mathrm{N}}$ and $g_{\mathrm{s}}$ in both species was divided into two groups by leaf temperatures above and below $30^{\circ} \mathrm{C}$ in the dry and wet seasons (Fig. 5). During the dry season, in S. macrophylla, a significantly positive linear correlation and similar slope was observed between $P_{\mathrm{N}}$ and $g_{\mathrm{s}}$ regardless of the $T_{\mathrm{l}}$. In the wet season, however, the linear slope at low $T_{1}$ was higher than that at high $T_{\mathrm{l}}$. In contrast, $P_{\mathrm{N}}$ and $g_{\mathrm{s}}$ in $M$. azedarach had a similar slope regardless of the $T_{1}$ in the wet season.

Table 2 Correlation between photosynthetic variables and environmental factors in Swietenia macrophylla and Melia azedarach during the dry and wet seasons

\begin{tabular}{|c|c|c|c|c|c|c|c|c|c|}
\hline & \multicolumn{8}{|c|}{ Environmental factors $^{a}$} & \multirow[t]{2}{*}{$\mathrm{CO}_{2}$} \\
\hline & $g_{\mathrm{s}}$ & $c_{\mathbf{i}}$ & $E$ & $\mathrm{VPD}_{\mathrm{a}}$ & $\mathrm{VPD}_{\mathbf{I}}$ & $T_{\mathrm{a}}$ & $T_{1}$ & PPFD & \\
\hline \multicolumn{10}{|c|}{ Dry season } \\
\hline$P_{\mathrm{N}}$ & $\mathrm{ns} / \mathrm{ns}$ & $-{ }^{* *} /-^{* *}$ & $\mathrm{~ns} / \mathrm{ns}$ & $\mathrm{ns} / \mathrm{ns}$ & $\mathrm{ns} /+^{*}$ & $\mathrm{~ns} / \mathrm{ns}$ & $-* / \mathrm{ns}$ & $\mathrm{ns} /+^{* *}$ & $\mathrm{~ns} / \mathrm{ns}$ \\
\hline$g_{\mathrm{s}}$ & & $\mathrm{ns} /+^{* *}$ & $+{ }^{* *} /+^{* *}$ & $\mathrm{~ns} / \mathrm{ns}$ & $\mathrm{ns} /-^{* *}$ & $\mathrm{~ns} / \mathrm{ns}$ & $\mathrm{ns} / \mathrm{ns}$ & $\mathrm{ns} / \mathrm{ns}$ & $\mathrm{ns} /+^{*}$ \\
\hline$C_{\mathrm{i}}$ & & & ns/ns & $\mathrm{ns} /-^{*}$ & $\mathrm{~ns} /-^{* *}$ & $\mathrm{~ns} / \mathrm{ns}$ & ns/ns & $\mathrm{ns} /-^{* *}$ & $\mathrm{~ns} /+^{* *}$ \\
\hline E & & & & ns/ns & $\mathrm{ns} / \mathrm{ns}$ & $\mathrm{ns} / \mathrm{ns}$ & $\mathrm{ns} /+^{*}$ & $\mathrm{~ns} / \mathrm{ns}$ & ns/ns \\
\hline \multicolumn{10}{|c|}{ Wet season } \\
\hline$P_{\mathrm{N}}$ & $+{ }^{* *} / \mathrm{ns}$ & $\mathrm{ns} /-^{*}$ & $+* * / n s$ & $\mathrm{~ns} / \mathrm{ns}$ & $\mathrm{ns} / \mathrm{ns}$ & $-{ }^{* *} / \mathrm{ns}$ & $-{ }^{* *} / \mathrm{ns}$ & $\mathrm{ns} / \mathrm{ns}$ & $\mathrm{ns} / \mathrm{ns}$ \\
\hline$g_{\mathrm{s}}$ & & $\mathrm{ns} /+^{* *}$ & $+{ }^{* *} /+^{* *}$ & $\mathrm{~ns} /-^{* *}$ & $\mathrm{~ns} /-^{* *}$ & $\mathrm{~ns} / \mathrm{ns}$ & $-{ }^{*} /+^{*}$ & $\mathrm{~ns} / \mathrm{ns}$ & $\mathrm{ns} / \mathrm{ns}$ \\
\hline$C_{\mathrm{i}}$ & & & $\mathrm{ns} /+^{*}$ & $\mathrm{~ns} /-^{* *}$ & $\mathrm{~ns} /-^{* *}$ & $\mathrm{~ns} / \mathrm{ns}$ & $\mathrm{ns} /+^{*}$ & $\mathrm{~ns} /-^{* *}$ & $\mathrm{~ns} / \mathrm{ns}$ \\
\hline E & & & & $\mathrm{ns} / \mathrm{ns}$ & $\mathrm{ns} / \mathrm{ns}$ & $\mathrm{ns} /+^{* *}$ & $\mathrm{~ns} /+^{* *}$ & $\mathrm{~ns} / \mathrm{ns}$ & $\mathrm{ns} /$ - $^{* *}$ \\
\hline
\end{tabular}

+ and - symbols represent positive and negative correlation, respectively

ns indicates no significant correlation

**** Indicate significance at $P<0.05$ and $P<0.01$, respectively. $\mathrm{N}=18$

${ }^{a} g_{\mathrm{s}}$ (stomatal conductance), $C_{\mathrm{i}}$ (intercellular $\mathrm{CO}_{2}$ concentration), $E$ (transpiration rate), $\mathrm{VPD}_{\mathrm{a}}$ (air vapor pressure deficit), $\mathrm{VPD}$ (leaf-air vapor pressure deficit), $T_{\mathrm{a}}$ (air temperature), $T_{1}$ (leaf temperature), PPFD (photosynthetic photon flux density), $\mathrm{CO}_{2}$ (ambient $\mathrm{CO}_{2}$ concentration), S. macrophylla/M. azedarach 


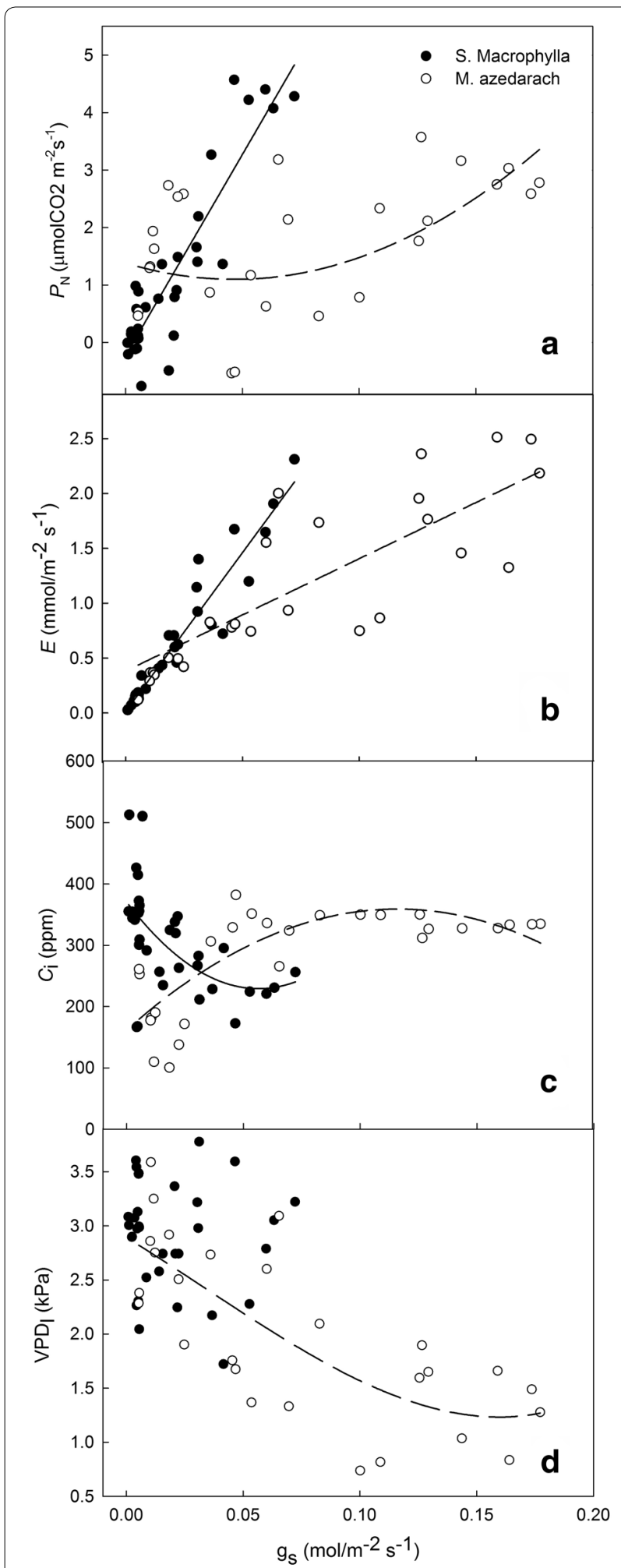

Fig. 4 Relationship between stomatal conductance $\left(g_{s}\right)$ and other gas exchange variables in Swietenia macrophylla and Melia azedarach $(N=36)$. Net photosynthetic rate $\left(P_{N} ; \mathbf{a}\right)$, transpiration $\left(E_{;} \mathbf{b}\right)$, intercellular $\mathrm{CO}_{2}$ concentration $\left(C_{i} ; \mathbf{c}\right)$, and vapor pressure deficit $\left(\mathrm{VPD}_{\mid} ; \mathbf{d}\right)$

\section{Discussion}

The influence of many environmental factors on photosynthesis and plant growth have been well researched in recent decades (Colom and Vazzana 2003; Ogaya and Peñuelas 2003; Li and Chen 2009). Zhang et al. (2009) suggested that a cool dry season of 4 months may have long-lasting negative effects on the physiology of Dipterocarpaceae trees in southern China. Similarly, the prolonged drought in 2010 may have influenced the $P_{\mathrm{N}}$ and $g_{\mathrm{s}}$ of the trees in our experimental plantation. Gasexchange dynamics may reflect the ability of a plant to maintain its photosynthetic apparatus under various environmental conditions (Ngugi et al. 2004; Ding et al. 2006). Therefore, we compared diurnal gas-exchange variables across dry and wet seasons in the two tree species.

Midday depression in leaf photosynthesis is common in the canopy leaves of tropical forests which is caused by high temperature, irradiance, or VPD (Ding et al. 2006; $\mathrm{Li}$ and Chen 2009; Zhang et al. 2009; Gao et al. 2015). Both species examined in this study exhibited a midday depression in leaf photosynthesis and recovered after 14:00, regardless of the season. These patterns indicate that environmental factors may limit photosynthesis in tropical forests during the midday period, which is consistent with the observations in other evergreen communities during seasonal drought (Koch et al. 1994). Under typical conditions, photosynthetic rates usually increase with PPFD, but in both seasons in our study, the $P_{\mathrm{N}}$ in $S$. macrophylla was negatively correlated $(P<0.01)$ with $T_{1}$ and not correlated with PPFD. However, temperature directly influenced VPD which is an important environment factor affected the leaf gas exchange. Previous estimations based on gas-exchange in peach-palm trees under subtropical conditions indicated that temperature and VPD have stronger effects on $P_{\mathrm{N}}$ compared with PPFD (Tucci et al. 2010).

During the late wet season in our study, the variation in $P_{\mathrm{N}}$ was similar in both species-the $P_{\mathrm{N}}$ decreased as PPFD decreased after 13:00. Our results concur with a research on S. macrophylla seedlings in northern Brazil, where under well-watered conditions gas exchange decreased as PPFD decreased after 13:00, reaching a minimum at 17:00, whereas $g_{\mathrm{s}}$ remained low under drought conditions (Cordeiro et al. 2009). Although comparisons of plant physiology between greenhouse and field conditions are limited due to differences in plant age, root depth, and the degree of control of environmental factors (Cordeiro et al. 2009), the similar decreases in $P_{\mathrm{N}}$ and $g_{\mathrm{s}}$ measured in the present field study and previous greenhouse studies suggest that stomatal conductance dominates transpiration and strongly affects photosynthesis in both our experimental species. 


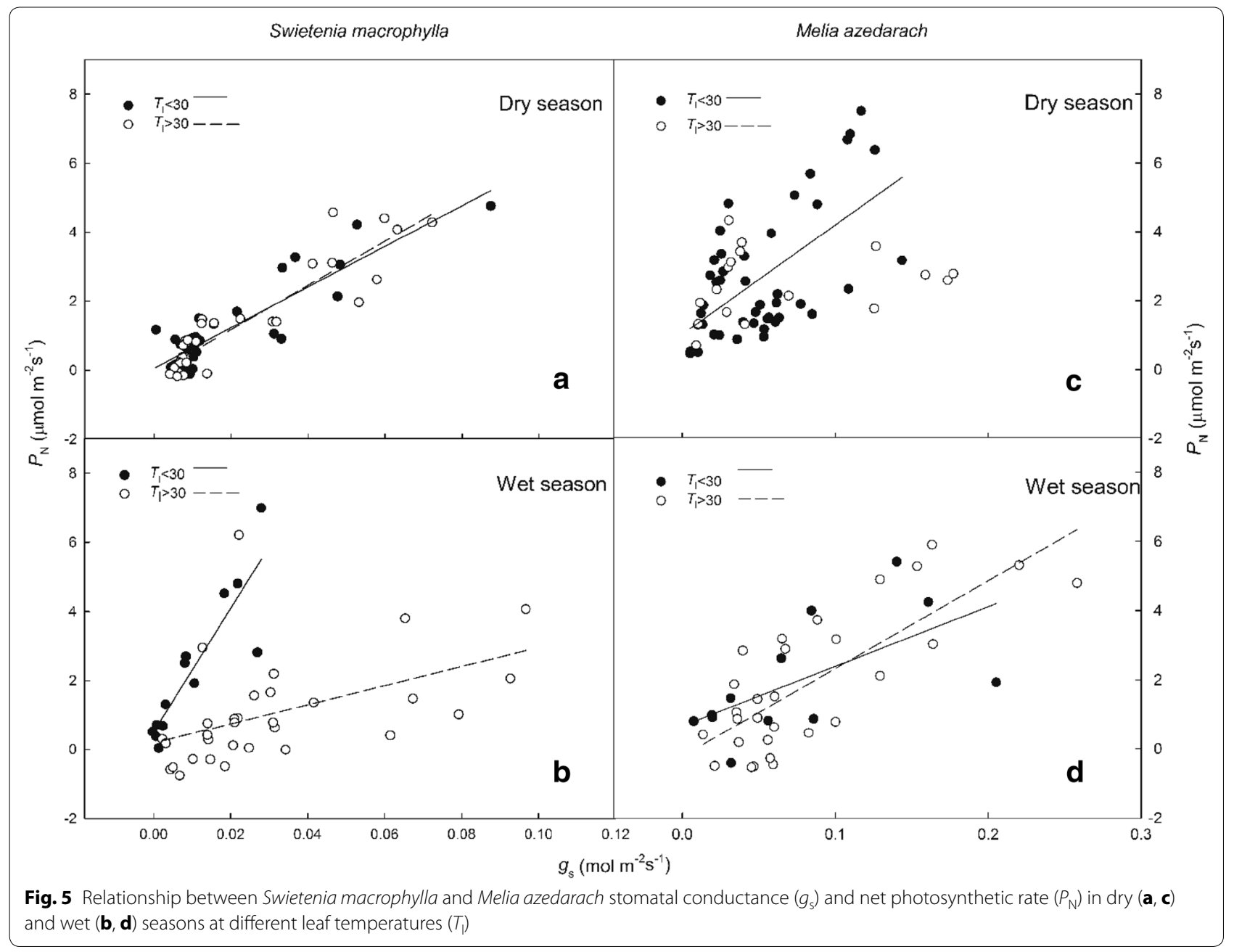

VPD is an important factor in plant gas exchange, because stomatal opening and closing are strongly dependent on VPD conditions (Cordeiro et al. 2009; $\mathrm{Li}$ and Chen 2009; Tucci et al. 2010; Niinemets and Keenan 2014; Chen et al. 2016b). For example, in Fritillaria cirrhosa, VPD increased sharply after 10:00, while $g_{\mathrm{s}}$ dropped rapidly (Li and Chen 2009), suggesting that $g_{\mathrm{s}}$ in this species is influenced by the environment. A study on Dialium pachyphyllum in Cameroon demonstrated similar results in that species (Koch et al. 1994). Here, we found a significant negative relationship between $g_{\mathrm{s}}$ and $\mathrm{VPD}_{1}(P<0.01)$ in $M$. azedarach, which might suggest a mechanism for water loss prevention. We also observed a negative relationship between $g_{\mathrm{s}}$ and $T_{1}$ in S. macrophylla during the wet season. Together, these results show that stomata are sensitive to environmental conditions and they close at $\mathrm{VPD}_{1}$ above $3 \mathrm{kPa}$, even in the wet season, in $M$. azedarach. Furthermore, a higher $T_{1}$ may be the cause of increased $\mathrm{VPD}_{1}$ that is accompanied by lower $g_{\mathrm{s}}$ and $E$ in S. macrophylla.
The variation of the leaf area not only reflects the phenology of plantations but also the effects of environmental stress. Thus, there is a strong relationship between LAI and diurnal climate (Hardwick et al. 2015). In $S$. macrophylla, the LAI was reduced only slightly during the dry season, but in $M$. azedarach, more than half of the total leaves fell. Therefore, the different drought tolerance strategies in these species represent the different ways in which they prevent water loss. Arndt et al. (2015) showed that compared to eucalypt savanna, the African mahogany (Khaya senegalensis) significantly reduced the total leaf area to moderate water loss in the dry season. Thus, the coordination between plant physiology and leaf area is important for drought adaptation.

Ngugi et al. (2004) reported a non-linear relationship between leaf photosynthesis and $g_{\mathrm{s}}$ in Eucalyptus argophloia and E. cloeziana. However, Sun et al. (1995) found a significant linear relationship between leaf photosynthesis and $g_{\mathrm{s}}$ in drought-resistant Nothofagus solan$d r i$, and less so in drought-susceptible $N$. menziesii. In 
our study, $P_{\mathrm{N}}$ and $g_{\mathrm{s}}$ in $M$. azedarach exhibited a curvilinear relationship during the wet season, whereas under drought $\left(g_{\mathrm{s}}<0.05 \mathrm{~mol} / \mathrm{m}^{2} / \mathrm{s}\right)$, the relationship became linear with a steeper slope than that measured in S. macrophylla. This steeper slope demonstrates that $M$. azedarach is more drought-resistant than S. macrophylla. Generally, the optimum temperature for photosynthesis ranges from 25 to $30{ }^{\circ} \mathrm{C}$ for tropical and subtropical broadleaved trees (Larch 1995). The higher leaf temperatures in S. macrophylla compared with those in M. azedarach may be the cause of the lower $g_{\mathrm{s}}$ in warm-wet seasons, leading to lower $P_{\mathrm{N}}$ (Fig. 5). Additionally, the curvilinear relationship between $C_{\mathrm{i}}$ and $g_{\mathrm{s}}$ in $M$. azedarach indicates that $C_{\mathrm{i}}$ increased with $g_{\mathrm{s}}$ until a certain $\mathrm{CO}_{2}$ concentration was reached, at which point $C_{\mathrm{i}}$ stabilized whenever $g_{s}$ increased. Colom and Vazzana (2003) found similar evidence for water-stressed Eragrostis curvula, and studies on Quercus pubescens during a dry summer also demonstrated that $C_{i}$ remains constant due to metabolic limitations or some degree of mesophyll resistance (Haldimann et al. 2008). In S. macrophylla, $C_{\mathrm{i}}$ decreased with increasing $g_{\mathrm{s}}$ during the dry season, and then increased with $g_{\mathrm{s}}$ during the wet season, demonstrating the effects of non-stomatal limitations on photosynthesis. Similarly, Koller et al. (2013) found that high $C_{\mathrm{i}}$ at low $g_{s}$ indicates an effect of non-stomatal limitation on photosynthesis in three Quercus species. In M. azedarach, the negative linear relationship between $g_{\mathrm{s}}$ and $\mathrm{VPD}_{1}$ during the dry season $\left(\mathrm{VPD}_{1}>1.5 \mathrm{kPa}\right)$ indicates the effects of stomatal limitation on photosynthesis. The same conclusion was made by Zhang et al. (2009) who showed that in dipterocarp species $g_{s}$ at a given VPD is significantly reduced during the dry season. Photosynthesis is one of the most temperature-sensitive processes in plants (Yamori et al. 2014). In the wet season, a significant linear relationship between $P_{\mathrm{N}}$ and $g_{\mathrm{s}}(P<0.01)$ with different $T_{1}$ demonstrated that high temperature in summer months might suppress photosynthesis in S. macrophylla. The same conclusion was reached by Slot and Winter (2017), who suggested that the negative effect of rising temperatures on photosynthesis in tropical canopy leaves is almost entirely driven by stomatal processes.

In general, elevated WUE helps plants to adapt to water deficiency in arid regions (Aranda et al. 2007). However, plants with higher WUE demonstrate increased growth during the dry but not the wet season (Picotte et al. 2007). A study conducted in Mediterranean climates (Ogaya and Peñuelas 2003) demonstrated that, compared with mesic species (e.g., Quercus ilex), drought-resistant species such as Phillyrea latifolia typically experience lower photosynthetic rates and higher transpiration rates, which consequently result in lower WUE. However, during drought conditions, $P_{\mathrm{N}}$ and WUE in P. latifolia can equal or exceed those of Q. ilex. During the wet season in the present study, S. macrophylla had relatively higher $P_{\mathrm{N}}$ and WUE values but lower $E$ values compared with those in $M$. azedarach. During the dry season, $E$ values were very low in both species, but $M$. azedarach had higher WUE than did S. macrophylla. This outcome again suggests that $M$. azedarach is a more drought-resistant species when compared to $S$. macrophylla.

Seasonally dry ecosystems such as the Mediterranean or tropical monsoon regions present a challenge for plant growth and survival (Arndt et al. 2015). Noormets et al. (2008) reported that a spring drought might suppress forest canopy development such as leaf sprout and expansion and have long-lasting effects on the forest ecosystem carbon balance. This imbalance remains even when soil water availability improves. In this study, the prolonged drought from October 2009 to April 2010 might have not only decreased leaf photosynthesis but also impaired regional plant productivity. The impact of such stress is represented in the growth performances of $M$. azedarach and S. macrophylla (Table 1), where both species showed lower DBH and height compared to those in reported in a previous study in Taiwan (Liao et al. 2011).

\section{Conclusions}

Melia azedarach adapted to drought by reducing total leaf area and maintaining higher $P_{\mathrm{N}}, g_{\mathrm{s}}, E$, and WUE compared with those measured in S. macrophylla during the dry season. In contrast, $S$. macrophylla had a higher $P_{\mathrm{N}}$ compared with $M$. azedarach during the wet season and is therefore considered drought-susceptible. In both species, photosynthetic rates during the dry season were affected by multiple, complex environmental factors, but in $S$. macrophylla the temperature had the largest effect on photosynthetic rate during the wet season. However, based on the recovery of $P_{\mathrm{N}}$ patterns in both species during the morning hours, we propose that both $M$. azedarach and S. macrophylla acclimatized to the study site, although they differed in diurnal gas-exchange patterns and drought adaptation strategies. $M$. azedarach has better growth performance under prolonged drought compared with $S$. macrophylla. These findings provide information about photosynthesis under drought conditions that support constructive plantation strategies in tropical areas. More attention should be paid to studying the differences in the photosynthetic responses that are dependent on species and the environment because of the changing climate.

\section{Authors' contributions}

CIC and YNW conceived the study, participated in its design and coordination, and helped draft the manuscript. HCJ and JCY collected, analyzed, and interpreted the data. CIC and HCJ wrote the manuscript. YNW and CSW advised throughout the entire process of the experiment and manuscript preparation. All authors read and approved the final manuscript. 


\author{
Author details \\ ${ }^{1}$ The Experimental Forest, National Taiwan University, 55750 Nantou, Taiwan. \\ 2 Department of Forestry and Resource Conservation, National Taiwan Uni- \\ versity, 10617 Taipei, Taiwan. ${ }^{3}$ Biodiversity Research Center, Academia Sinica, \\ 11529 Taipei, Taiwan.
}

\section{Acknowledgements}

We thank the researchers at The Experimental Forest, National Taiwan University, for their help with data collection and field measurements. Many thanks also to the members of the Silviculture laboratory, School of Forestry and Resource Conservation, and to the National Taiwan University for their assistance and cooperation.

\section{Competing interests}

The authors declare that they have no competing interests.

\section{Availability of data and materials}

The dataset supporting the conclusions of this article is included within the article.

\section{Consent for publication}

Not applicable.

\section{Ethics approval and consent to participate}

Not applicable.

\section{Funding}

The author(s) received no specific funding for this work.

\section{Publisher's Note}

Springer Nature remains neutral with regard to jurisdictional claims in published maps and institutional affiliations.

Received: 16 July 2017 Accepted: 23 November 2017

Published online: 02 December 2017

\section{References}

Aranda I, Pardos M, Puértolas J, Jiménez MD, Pardos JA (2007) Water-use efficiency in cork oak (Quercus suber) is modified by the interaction of water and light availabilities. Tree Physiol 27:671-677

Arndt SK, Sanders GJ, Bristow M, Hutley LB, Beringer J, Livesley SJ (2015) Vulnerability of native savanna trees and exotic Khaya senegalensis to seasonal drought. Tree Physiol 35:783-791

Chen Cl, Wang YN, Lih XW, Liao YJ, Yu JC, Wu CS (2013) Growth and $\mathrm{CO}_{2}$ sequestration of Melia azedarach in Wan-long farm of Pingtung. Q J Chin For 46:125-134

Chen Cl, Yu JC, Wang YN (2016a) Growth and $\mathrm{CO}_{2}$ sequestration of Swietenia macrophylla in the Wan-long farm, Pingtung. Q J Chin For 48:331-342

Chen Cl, Wang YN, Lih HW, Yu JC (2016b) Three-year study on diurnal and seasonal $\mathrm{CO}_{2}$ sequestration of a young Fraxinus griffithii plantation in southern Taiwan. Forests 7:230

Cheng CH, Huang YH, Menyailo OV, Chen CT (2016) Stand development and aboveground biomass carbon accumulation with cropland afforestation in Taiwan. Taiwan J For Sci 31(2):105-118

Colom MR, Vazzana C (2003) Photosynthesis and PSII functionality of droughtresistant and drought-sensitive weeping lovegrass plant. Environ Exp Bot 49:135-144

Cordeiro YEM, Pinheiro HA, Santos Filho BG, Corrêa SS, Silva JRR, Dias-Filho MB (2009) Physiological and morphological responses of young mahogany (Swietenia macrophylla King) plants to drought. For Ecol Manage 258:1449-1455

Ding L, Wang KJ, Jiang GM, Li YG, Jiang CD, Liu MZ, Niu SL, Peng YM (2006) Diurnal variation of gas exchange, chlorophyll fluorescence, and xanthophyll cycle components of maize hybrids released in different years. Photosynthetica 44:26-31

Dünisch O, Montóia VR, Bauch J (2003) Dendroecological investigations on Swietenia macrophylla King and Cedrela odorata L. (Meliaceae) in the central Amazon. Trees Struct Funct 17:244-250
Engelbrecht BMJ, Dalling JW, Pearson TRH, Wolf RL, Gálvez DA, Koehler T, Tyree MT, Kursar TA (2006) Short dry spells in the wet season increase mortality of tropical pioneer seedlings. Oecologia 148:258-269

Gao ZJ, Xu BC, Wang J, Huo LJ, Li S (2015) Diurnal and seasonal variations in photosynthetic characteristics of switchgrass in semiarid region on the Loess Plateau of China. Photosynthetica 53:489-498

Grogan J, Landis RM, Ashton MS, Galvăo J (2005) Growth response by big-leaf mahogany (Swietenia macrophylla) advance seedling regeneration to overhead canopy release in southeast Pará, Brazil. For Ecol Manage 204:399-412

Guerfel M, Ouni Y, Boujnah D, Zarrouk M (2009) Photosynthesis parameters and activities of enzymes of oxidative stress in two young 'Chemlali' and 'Chetoui' olive trees under water deficit. Photosynthetica 47:340-346

Haldimann P, Gallé A, Feller U (2008) Impact of an exceptionally hot dry summer on photosynthetic traits in oak (Quercus pubescens) leaves. Tree Physiol 28:785-795

Hardwick SR, Toumi R, Pfeifer M, Turner EC, Nilus R, Ewers RM (2015) The relationship between leaf area index and microclimate in tropical forest and oil palm plantation: forest disturbance drives changes in microclimate. Agric For Meteorol 201:187-195

IPCC (2015) Climate change 2014: synthesis report. Cambridge University Press, New York

Ishida A, Toma T, Matsumoto Y, Yap SK, Maruyama Y (1996) Diurnal changes in leaf gas exchange characteristics in the uppermost canopy of a rain forest tree, Dryobalanops aromatica Gaertn. f. Tree Physiol 16:779-785

Koch GW, Amthor JS, Goulden ML (1994) Diurnal patterns of leaf photosynthesis, conductance and water potential at the top of a lowland rain forest canopy in Cameroon: measurements from the Radeau des Cimes. Tree Physiol 14:347-360

Koller S, Holland V, Brüggemann W (2013) Effects of drought stress on the evergreen Quercus ilex L., the deciduous Q. robur L. and their hybrid Q. × turneri Willd. Photosynthetica 51:574-582

Kuo YL, Fan KS, Hwang CW, Lee YP, Wu HL, Tsay RF (2004) Gas exchange potential in sun-exposed leaves of 30 broadleaf tree species in Taiwan. Taiwan J For Sci 19:375-386

Larch W (1995) Physiological plant ecology, 3rd edn. Springer, Berlin

Leuzinger S, Zotz G, Asshoff R, Körner C (2005) Responses of deciduous forest trees to severe drought in Central Europe. Tree Physiol 25:641-650

Li XW, Chen SL (2009) Diurnal changes in gas exchange and chlorophyll fluorescence parameters of Fritillaria cirrhosa and F. delavayi under field conditions. Photosynthetica 47:191-198

Li S, Feifel M, Karimi Z, Schuldt B, Choat B, Jansen S (2016) Leaf gas exchange performance and the lethal water potential of five European species during drought. Tree Physiol 36:179-192

Liao WW, Lee MJ, Su PH (2004) Enhancing effects of chinaberry water extract treatment on anti-termite wood property of teak and Taiwan red pine. Q J Chin For 37:453-460

Liao YW, Chen MK, Chen YK, Chung YK, Wu ST (2011) Afforestation carbon storage of Taiwan sugar corporation in Ping-tung County. Q J Chin For 44:373-384

Ngugi MR, Doley D, Hunt MA, Ryan P, Dart P (2004) Physiological response to water stress in Eucalyptus cloeziana and E. argophloia seedlings. TreesStruct Funct 18:381-389

Niinemets Ü, Keenan T (2014) Photosynthetic responses to stress in Mediterranean evergreens: mechanisms and models. Environ Exp Bot 103:24-41

Noormets A, McNulty SG, DeForest JL, Sun G, Li Q, Chen J (2008) Drought during canopy development has lasting effect on annual carbon balance in a deciduous temperate forest. New Phytol 179:818-828

Ogaya R, Peñuelas J (2003) Comparative field study of Quercus ilex and Phillyrea latifolia: photosynthetic response to experimental drought conditions. Environ Exp Bot 50:137-148

Picotte JJ, Rosenthal DM, Rhode JM, Cruzan MB (2007) Plastic responses to temporal variation in moisture availability: consequences for water use efficiency and plant performance. Oecologia 153:821-832

Slot M, Winter K (2017) In situ temperature response of photosynthesis of 42 tree and liana species in the canopy of two Panamanian lowland tropical forests with contrasting rainfall regimes. New Phytol 214:1103-1117

Sun OJ, Sweet GB, Whitehead D, Buchan GD (1995) Physiological responses to water stress and waterlogging in Nothofagus species. Tree Physiol 15:629-638 
Sun SJ, Meng P, Zhang JS, Wan X (2011) Variation in soil water uptake and its effect on plant water status in Juglans regia $L$. during dry and wet seasons. Tree Physiol 31:1375-1389

Taiz L, Zeiger E (2002) Plant physiology, 3rd edn. Sinauer Associates, Sunderland

Toky OP, Bisht RP (1992) Observations on the rooting patterns of some agroforestry trees in an arid region of north-western India. Agrofor Syst 18:245-263

Tucci MLS, Erismann NM, Machado EC, Ribeiro RV (2010) Diurnal and seasonal variation in photosynthesis of peach palms grown under subtropical conditions. Photosynthetica 48:421-429
Yamori W, Hikosaka K, Way DA (2014) Temperature response of photosynthesis in $\mathrm{C}_{3}, \mathrm{C}_{4}$, and CAM plants: temperature acclimation and temperature adaptation. Photosynth Res 119:101-117

Yin CY, Berninger F, Li CY (2006) Photosynthetic responses of Populus przewalski subjected to drought stress. Photosynthetica 44:62-68

Zhang JL, Meng LZ, Cao KF (2009) Sustained diurnal photosynthetic depression in uppermost-canopy leaves of four dipterocarp species in the rainy and dry seasons: does photorespiration play a role in photoprotection? Tree Physiol 29:217-228

\section{Submit your manuscript to a SpringerOpen ${ }^{\circ}$ journal and benefit from:}

- Convenient online submission

- Rigorous peer review

- Open access: articles freely available online

- High visibility within the field

- Retaining the copyright to your article

Submit your next manuscript at $\boldsymbol{\nabla}$ springeropen.com 